\title{
Experimental Analysis of a Tubular type of Evaporative Heat Exchanger
}

\author{
A. Rajneesh, B. Raj Kumar
}

\begin{abstract}
The results of experimental investigations of a bundle of tubes of an evaporative tubular heat exchanger are presented in this article. Evaporative effectiveness and mass transfer coefficient are estimated over a wide range of operating conditions. Based on the experiments, correlations are derived using multiple regression analysis. Results show that as the cooling film flow rate increases, evaporative effectiveness and mass transfer coefficient increases provided that the air flow rate is constant which is flowing from underneath the tubes of the evaporative tubular heat exchanger. The tubes are subjected to simultaneous flows of cooling water from the top; air flows from underneath with controlled amount of relative humidity and the process fluid is flowing through the tubes. Developed correlations are helpful in improvement of the design of heat transfer devices and many other engineering applications. Consideration of Relative humidity as one operating variable leads to novelty in the present investigation.
\end{abstract}

Keywords- Evaporative effectiveness, mass transfer coefficient, Evaporative tubular heat exchanger, Correlations.

\section{Introduction}

Evaporative tubular heat exchanger is a device, which employs combination of water and air to dissipate energy from a hot water flowing inside the tube and its performance is generally influenced by heat and mass transfer coefficients. Higher the value of these coefficients, the greater would be the effectiveness of the evaporative tubular heat exchanger. Considerable increase in the rate of heat transfer between the atmospheric air and the circulating water can be achieved by bringing hot water into direct contact with moving water. This employs the principle of evaporative cooling of water well known since ancient times. Evaporative tubular heat exchangers have been utilized in the refrigeration, chemical, desalinization industries, and petroleum refining. The first patent of such an evaporative type of heat exchangers was registered in 1888 [1], only a few researchers worked in this area prior to the 1970's [2, 3]. In refrigeration and air conditioning applications, evaporative tubular heat exchanger possesses many advantages over flooded bundles of tubes as for flooded tube bundles, heat transfer surface, bundle geometry, and operating strategies have not been so refined so far. At present, these issues are motivating many researchers. Ganic et al. [4] investigated the mechanism of water film

Dr. Rajneesh is with the National Institute of Technology, Kurukshetra, Haryana, India

Dr. Raj Kumar is with Deenbandhu Chhotu Ram University of Science \& Technology, Murthal, Haryana, India. formation over a horizontal tube and conducted experiments with sub cooled water film over an electrically heated horizontal cylinder. Adiabatic film cooling effectiveness of different patterns measured using heat-mass transfer analogy method determined by Lin et al. [5], as an advanced cooling scheme to meet increasingly stringent combustor cooling requirements. Turbulent forced convective heat and mass transfer downstream of blockages with round and elongated holes in a rectangular channel was studied by Ahn et al. [6]. The performance of tubular heat exchanger operating under wet surface conditions investigated by Liu et al. [7] and studied the condensate retention and the attendant thermalhydraulic effect associated with changes in air-side surface wettability. Simultaneously, transitory time of adsorption is a key element when working with heat sensitive fluids such as in chemical and food products industries as stated by Alhusseini et al. [8]. Falling film dry out models and heat and mass transfer problems on various configurations and geometries have been studied by various researchers (Jiao et al. [9], Mikielewicz et al. [10], Volle et al. [11], Grigore et al. [12], Rahman et al. [13], Fan et al. [14], Bai. et al. [15] and Kumar et al. [16]).

The motivation behind the present work is to develop the correlations of evaporative effectiveness and mass transfer coefficient with dimensionless numbers viz. dimensionless enthalpy potential, Reynolds number of cooling water and Reynolds number of air for a wide range of relative humidity of up streaming air and other operating variables.

\section{Experimental Test Rig}

The schematic of experimental test rig fabricated for the present investigation is shown in Figure 1.

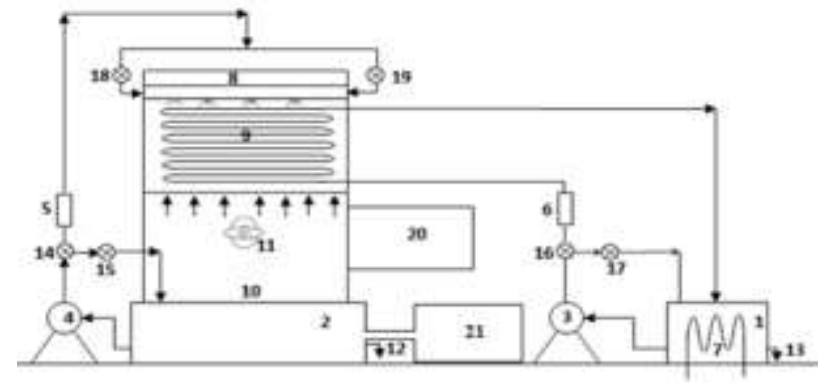

Figure 1. Schematic of evaporative tubular heat exchanger test rig

1: Hot water reservoir. 2: Cooling water reservoir.

3: Hot water Supply Pump. 4: Cooling water supply pump.

5-6: Digital flow meters. 7: Heating elements.

8: Cooling water spray pipe. 9: Test section with bundle of tubes. 10: Air duct. 11: Axial flow blower. 12-13: Drains.

14-19: Flow control valves. 20: Humidifier. 21: Feeder tank. 
A bundle having eight rows of copper tubes, each row consisting of eight copper tubes, arranged in a staggered way was used in the present investigation. The inner and outer diameters of the tubes used were $0.0234 \mathrm{~m}$ and $0.0254 \mathrm{~m}$, respectively. Area of cross-section of the test section in the direction of air flow $\left(\mathrm{A}_{\mathrm{t}}\right)$ was $0.3960 \mathrm{~m}^{2}$. The arrangement of cooling water spray system consisting of eight spray pipes was fitted over the test section to spray water droplets exactly over the tubes of bundle. The inner and outer diameters of the spray pipes were $0.0265 \mathrm{~m}$ and $0.0340 \mathrm{~m}$, respectively. All the temperature sensors used to record the temperature at various locations were connected to a 32-channel programmable data logger. The mass flow rates of cooling water and hot water were measured by calibrated flow meters with digital display. The velocity of air leaving the test section from the top was measured at different locations to find the average velocity by calibrated anemometer with digital display. The relative humidity of up streaming air was varied at inlet of the test unit with the help of humidifier in the range of $50 \%$ to $90 \%$ and was measured with help of digital hand held Hygrothermometer. The instruments used with their resolutions and accuracies are given in Table I.

TABLE I. INSTRUMENTS USED WITH THEIR RESOLUTIONS AND ACCURACIES

\begin{tabular}{lll}
\hline $\begin{array}{l}\text { N } \\
\text { o. }\end{array}$ & Instrument & Resolution and Accuracy \\
\hline 1 & $\begin{array}{l}\text { RTD sensors } \\
(\mathrm{PT}-100)\end{array}$ & Resolution: $0.1^{\circ} \mathrm{C}$ and \% of error in accuracy: $\pm 1.5 \%$ \\
\hline 2 & $\begin{array}{l}\text { Data logger } \\
(32-\text {-channel })\end{array}$ & Resolution: $0.1^{\circ} \mathrm{C}$ \\
\hline 3 & Flow meters & $\begin{array}{l}\text { Resolution: } 1.66 \mathrm{~kg} / \mathrm{s} \text { and } \% \text { of error in accuracy: } \\
\pm 3.0 \%\end{array}$ \\
\hline 4 & Anemometer & Resolution: $0.1 \mathrm{~m} / \mathrm{s}$ and \% of error in accuracy: $\pm 2 \%$ \\
\hline 5 & $\begin{array}{l}\text { Hygro- } \\
\text { thermometer }\end{array}$ & Resolution: $0.1 \%$ and \% of error in accuracy: $\pm 2 \%$ \\
\hline
\end{tabular}

\section{Experimental Procedure}

In the case of first type of flow conditions, the flow rate of cooling water was varied as mentioned in Table II, keeping the mass flow rate of hot water constant. A steady state was achieved for the observations, the temperature of hot water at the inlet and at the outlet of the tubes, the temperature of cooling water at the inlet of spray pipe \& just below the test unit, the average temperature of tube surface, the mass flow rates of hot and cold water were recorded.

For the first, second, third, fourth and fifth set of observations, the above set was repeated for second type of flow conditions. Air velocity at the top of the test section was fixed at $0.8 \mathrm{~m} / \mathrm{s}$. Relative humidity at the inlet of the test section was varied from $50 \%$ to $90 \%$. A steady state was achieved for all the observations, the temperatures and the mass flow rates as stated above in the first type of flow conditions, dry bulb \& wet bulb temperatures of air at the inlet of test section, relative humidity of up-streaming air and velocity of air at the top of test section were recorded.

The above five sets of experiments were repeated for air velocities at the top of test section at $1.6 \mathrm{~m} / \mathrm{s}, 2.4 \mathrm{~m} / \mathrm{s}, 3.2 \mathrm{~m} / \mathrm{s}$ and $4.0 \mathrm{~m} / \mathrm{s}$ to get 125 observations in total. All the quantities as stated above were recorded for each observation. The ranges of operating variables are given in Table II.

TABLE II. RANGES OF OPERATING VARIABLES

\begin{tabular}{llllc}
\hline Fluid & $\begin{array}{l}\text { Mass flow } \\
\text { rate } \\
(\mathbf{k g} / \mathbf{s})\end{array}$ & $\begin{array}{l}\text { Temp. } \\
\text { at inlet } \\
\text { (oC) }\end{array}$ & $\begin{array}{l}\text { Velocity } \\
(\mathbf{m} / \mathbf{s})\end{array}$ & Reynolds number \\
\hline $\begin{array}{l}\text { Process } \\
\text { fluid }\end{array}$ & 0.20 to 0.60 & $55.0 \pm 1.0$ & $\ldots \ldots$ & 1697 to 5254 \\
\hline $\begin{array}{l}\text { Cooling } \\
\text { water }\end{array}$ & 0.08 to 0.16 & $27.0 \pm 1.0$ & $\ldots \ldots$ & 60 to 110 \\
\hline Air & $\ldots \ldots$ & $27.0 \pm 2.0$ & 0.8 to 4.0 & 1245 to 6395 \\
\hline
\end{tabular}

\section{Iv. Governing Equations}

The heat dissipation rate from the tubes, when both air and cooling water flowing simultaneously can be written as:

$$
Q_{w a}=W_{h} C_{p}\left(t_{h 1}-t_{h 2}\right)
$$

Reynolds number of air and cooling water are determined as:

$$
\begin{gathered}
R e_{a}=\frac{\rho_{a} V_{t} D_{o}}{\mu_{a}} \\
R e_{w}=\frac{4 \Gamma}{\mu_{w}}
\end{gathered}
$$

Liquid film flow rate of cooling water per unit length of the tube, $\Gamma$ given as:

$$
\Gamma=\frac{W_{w}}{2 l}
$$

where, $l$ is the active length of a tube and is taken as $38.4 \mathrm{~m}$ and $W_{w}$ is the mass flow rate of cooling water.

Mass transfer coefficient $(K)$ is calculated from:

$$
K=\frac{Q_{w a}}{A_{o}\left(i_{s}-i_{a}\right)}
$$

where, $\left(i_{s}-i_{a}\right)$ is the enthalpy potential, the difference of enthalpy of saturated air at the average tube surface temperature and the enthalpy of air at the inlet of heat exchanger. $\left(A_{o}\right)$ is the outside surface area of the tube and is calculated as $3.064 \mathrm{~m}^{2}$.

Evaporative effectiveness $(E E)$ of heat exchanger can be expressed as:

$$
E E=\frac{Q_{w a}}{Q_{w}}
$$

where, $Q_{w}$ is the heat dissipation rate from the tubes, when only cooling water flowing at same operating conditions and is calculated as:

$$
W_{w}=W_{h} C_{p}\left(t_{h 1}-t_{h 2}\right)
$$

\section{v. Results and Discussion}

A multiple regression analysis of the experimental data collected for evaporative heat exchanger are used to find the correlations and to improve the system performance in concern with evaporative effectiveness.

Evaporative effectiveness with dimensionless enthalpy potential, film Reynolds number of cooling water and Reynolds number of air with the \% mean and standard deviation of -0.11 and 4.72 , respectively are correlated as:

$$
E E=86.65(E P)_{d l}^{0.81}\left(R e_{w}\right)^{0.41}\left(R e_{a}\right)^{-0.05}
$$

(For $\quad 1262.43 \leq \operatorname{Re}_{\mathrm{a}} \leq 6395.02 ; \quad 60 \leq \operatorname{Re}_{\mathrm{w}} \leq 110 ; \quad 0.027 \leq(\mathrm{EP})_{\mathrm{dl}} \leq$ $0.036 ; 50 \% \leq \phi \leq 60 \%)$ 
Evaporative effectiveness with dimensionless enthalpy potential, film Reynolds number of cooling water and Reynolds number of air with the $\%$ mean and standard deviation of -0.58 and 4.82 , respectively are correlated as:

$$
E E=154.41(E P)_{d l}^{0.34}\left(R e_{w}\right)^{0.34}\left(R e_{a}\right)^{-0.37}
$$

(For $1243.62 \leq \mathrm{Re}_{\mathrm{a}} \leq 6365.64 ; \quad 60 \leq \mathrm{Re}_{\mathrm{w}} \leq 110 ; \quad 0.029 \leq(\mathrm{EP})_{\mathrm{dl}} \leq$ $0.043 ; 70 \% \leq \phi \leq 90 \%)$

The correlations developed for evaporative effectiveness show a good agreement between experimental and predicted values of evaporative effectiveness with an error of $\pm 5.0 \%$.

Mass transfer coefficient with dimensionless enthalpy potential, film Reynolds number of cooling water and Reynolds number of air with the \% mean and standard deviation of 0.05 and 4.80, respectively are correlated as:

$K=1.16 \times 10^{-3}(E P)_{d l}^{-3.74}\left(R e_{w}\right)^{0.13}\left(R e_{a}\right)^{0.42} \mathrm{~kg} / \mathrm{m}^{2} \mathrm{~s} \quad(10)$ (For $\quad 1262.43 \leq \mathrm{Re}_{\mathrm{a}} \leq 6395.02 ; \quad 60 \leq \mathrm{Re}_{\mathrm{w}} \leq 110 ; \quad 0.027 \leq(\mathrm{EP})_{\mathrm{dl}} \leq$ $0.036 ; 50 \% \leq \phi \leq 60 \%$ )

Mass transfer coefficient with dimensionless enthalpy potential, film Reynolds number of cooling water and Reynolds number of air with the $\%$ mean and standard deviation of -0.38 and 4.81 , respectively are correlated as:

$$
K=1.21 \times 10^{-3}(E P)_{d l}^{-6.25}\left(R e_{w}\right)^{0.47}\left(R e_{a}\right)^{0.43} \mathrm{~kg} / \mathrm{m}^{2} \mathrm{~s} \quad(11)
$$

(For $\quad 1243.62 \leq \mathrm{Re}_{\mathrm{a}} \leq 6365.64 ; \quad 60 \leq \mathrm{Re}_{\mathrm{w}} \leq 110 ; \quad 0.029 \leq(\mathrm{EP})_{\mathrm{dl}} \leq$ $0.043 ; 70 \% \leq \phi \leq 90 \%)$

The correlations developed for mass transfer coefficient show a good agreement between experimental and predicted values of mass transfer coefficient with an error of $\pm 5 \%$.

The quantitative effects of film Reynolds number of cooling water on heat flux and mass transfer coefficient are shown graphically for relative humidity of up streaming air at $50 \%$, $60 \%, 70 \%, 80 \%$ and 90\%, in Figures (2-6), respectively.

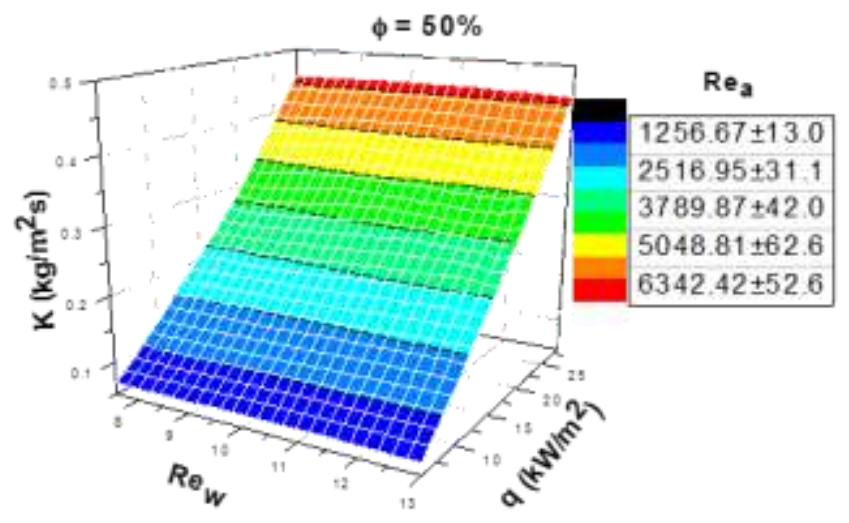

Figure 2. Effect of film Reynolds number of cooling water on the heat flux and mass transfer coefficient at $\phi=50 \%$

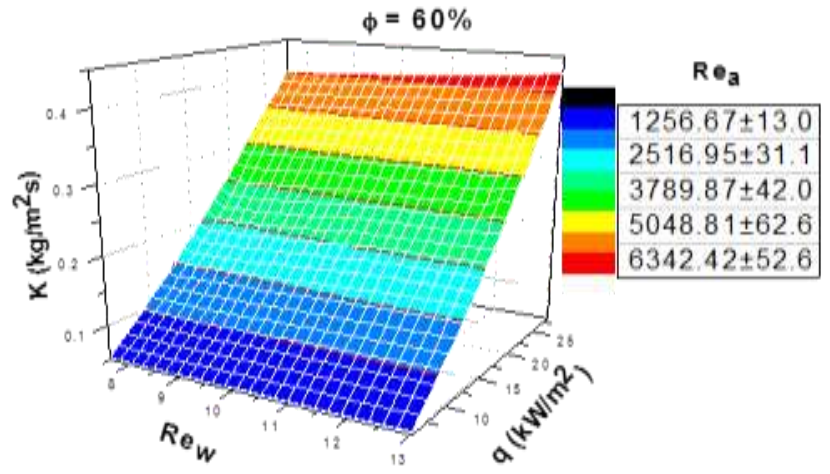

Figure 3. Effect of Reynolds number of cooling water on the heat flux and mass transfer coefficient at $\phi=60 \%$

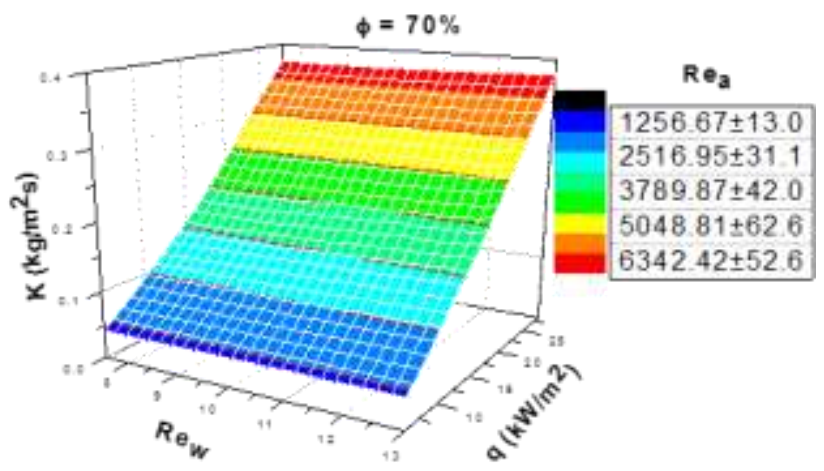

Figure 4. Effect of film Reynolds number of cooling water on the heat flux and mass transfer coefficient at $\phi=70 \%$

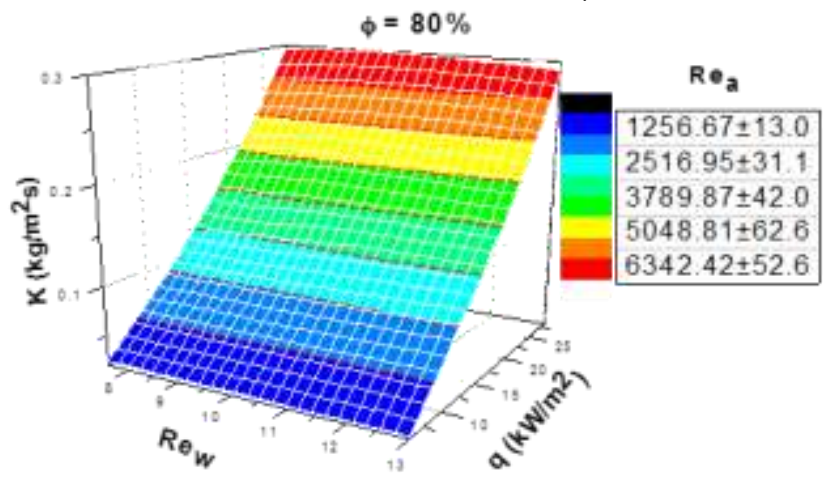

Figure 5. Effect of film Reynolds number of cooling water on the heat flux and mass transfer coefficient at $\phi=80 \%$

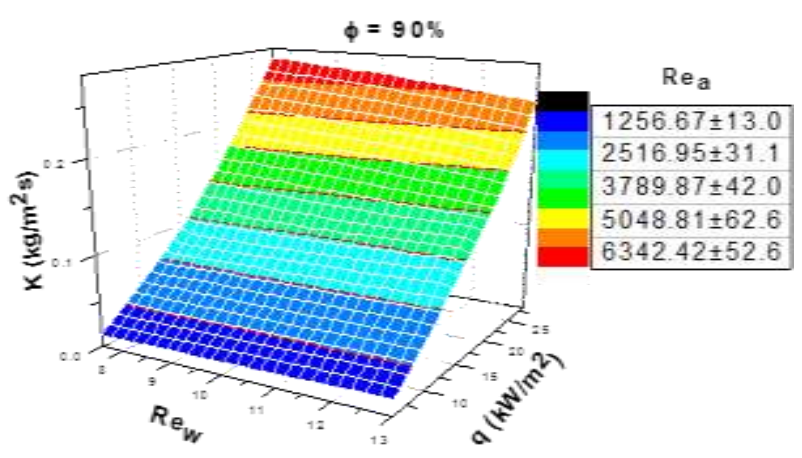

Figure 6. Effect of film Reynolds number of cooling water on the heat flux and mass transfer coefficient at $\phi=90 \%$ 
The quantitative effects of dimensionless enthalpy potential on evaporative effectiveness for a bundle of horizontal tubes of an evaporative tubular heat exchanger are shown graphically for relative humidity of up streaming air at $50 \%$, $60 \%, 70 \%, 80 \%$ and 90\%, in Figures (7-11), respectively.

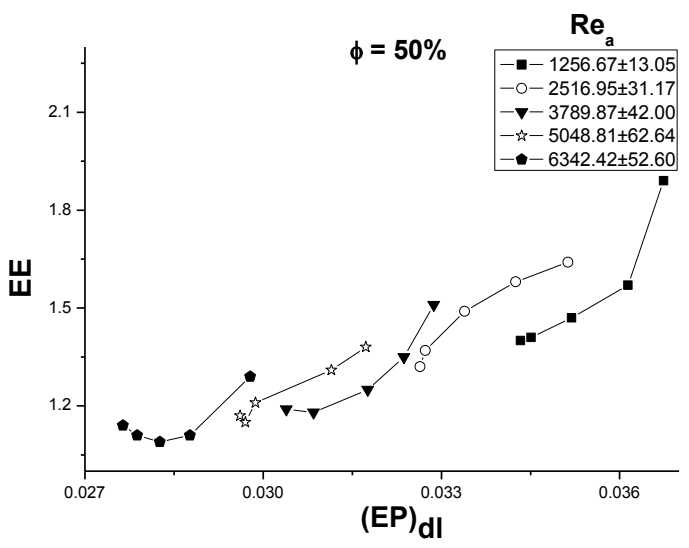

Figure 7. Effect of dimensionless enthalpy potential on evaporative effectiveness at $\phi=50 \%$

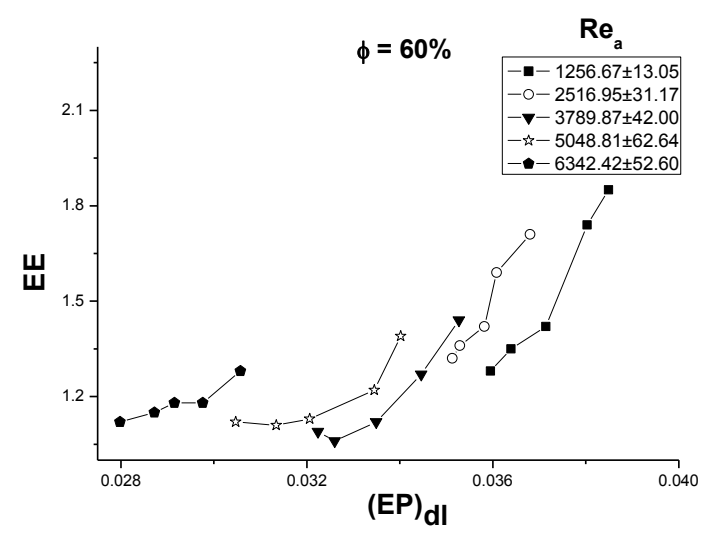

Figure 8. Effect of dimensionless enthalpy potential on evaporative effectiveness at $\phi=60 \%$

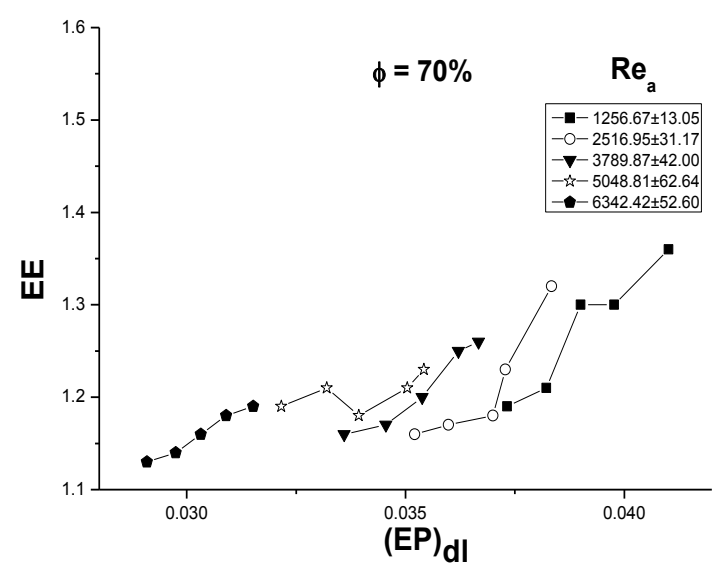

Figure 9. Effect of dimensionless enthalpy potential on evaporative effectiveness at $\phi=70 \%$

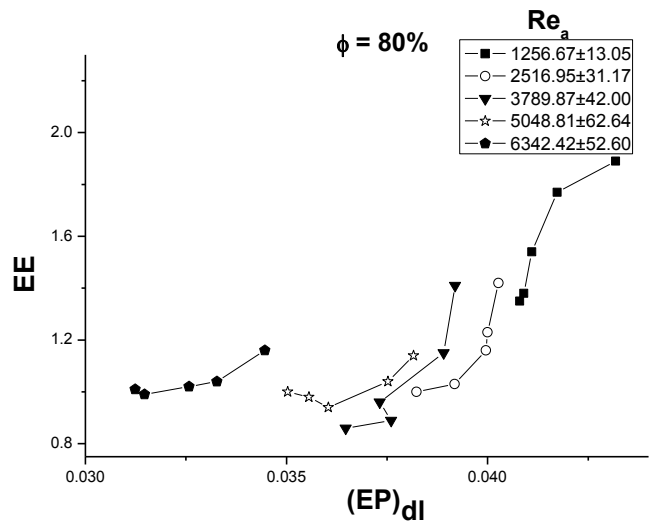

Figure 10. Effect of dimensionless enthalpy potential on evaporative effectiveness at $\phi=80 \%$

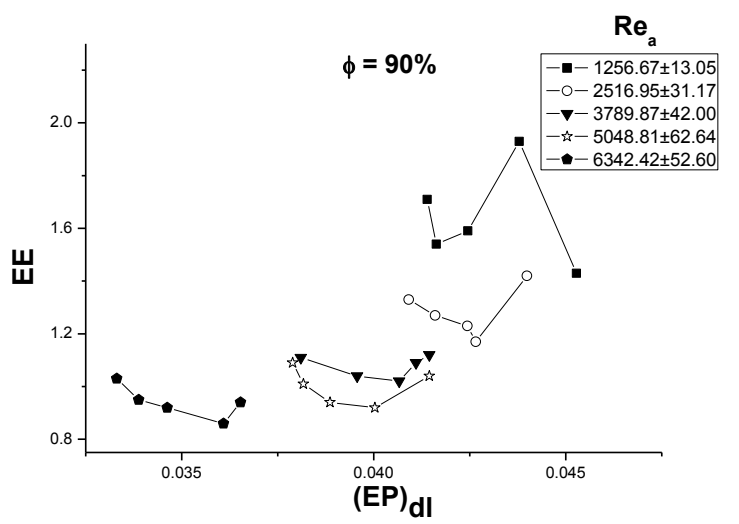

Figure 11. Effect of dimensionless enthalpy potential on evaporative effectiveness at $\phi=90 \%$

It is conspicuous from the results that the evaporative effectiveness does not change significantly with Reynolds number of air over a given set of film Reynolds number of cooling water

At certain values of film Reynolds number of cooling water and Reynolds number of air, the maximum values of the mass transfer coefficient i.e $0.4540 \mathrm{~kg} / \mathrm{m}^{2} \mathrm{~s}$ are achieved at $50 \%$ relative humidity of up streaming air.

The maximum value of evaporative effectiveness can be observed from the results shown graphically for a given set of operating conditions. For the present case of a bundle of tubes, the maximum value of evaporative effectiveness is found as 1.96 at $50 \%$ relative humidity. Thus the systems of similar configurations subjected to similar operating conditions may be operated to get maximum evaporative effectiveness and to conserve the energy as well.

The quantitative changes in evaporative effectiveness and mass transfer coefficient are quite interesting. The increase in evaporative effectiveness with dimensionless enthalpy potential at $70 \%$ relative humidity is found to be lowest at specified range of Reynolds number of air. Whereas, the mass transfer coefficient with film Reynolds number of cooling water is found to be increased substantially from $9 \%$ to $126 \%$ at $80 \%$ relative humidity and from $9 \%$ to $225 \%$ at $90 \%$ relative humidity. 
Proc. of the Intl. Conf. on Advances in Civil, Structural and Mechanical Engineering - ACSM 2015.

Copyright (C) Institute of Research Engineers and Doctors, USA .All rights reserved.

ISBN: 978-1-63248-039-2 doi: 10.15224/ 978-1-63248-039-2-24

\section{vi. Conclusion}

Precise and easy to use correlations for evaporative effectiveness and mass transfer coefficient in terms of dimensionless numbers developed for a wide range of operating conditions and would save a considerable time in estimating the design parameters also to predict the performance of heat exchangers of similar configuration.

\section{Acknowledgment}

The test facility support of the National Institute of Technology, Kurukshetra, India is gratefully acknowledged.

\section{Nomenclature}

A: Area, $\mathrm{m}^{2}$

$C_{p}$ : Specific heat of water at constant pressure, $\mathrm{J} / \mathrm{kgK}$

$E E$ : Evaporative effectiveness

$E P$ : Enthalpy potential

$i$ : Enthalpy, $\mathrm{J} / \mathrm{kg}$

$K$ : Mass transfer coefficient, $\mathrm{kg} / \mathrm{m}^{2} \mathrm{~s}$

$q$ : Heat flux, $\mathrm{kW} / \mathrm{m}^{2}$

$Q$ : Heat flow rate, $\mathrm{W}$

$R e$ : Reynolds number

$t$ : Temperature, ${ }^{\circ} \mathrm{C}$

$V$ : Velocity of air, $\mathrm{m} / \mathrm{s}$

$W$ : Mass flow rate, $\mathrm{kg} / \mathrm{s}$

\section{Greek Symbols}

$\Gamma$ : Film flow rate, $\mathrm{kg} / \mathrm{ms}$

$\mu$ : Dynamic viscosity, Ns/m

$\rho$ : Density, $\mathrm{kg} / \mathrm{m}^{3}$

$\phi:$ Relative humidity, $\%$

\section{Subscripts}

$a$ : Air

$d l$ : Dimensionless

$h$ : Hot water

$s$ : Saturated air at average wall temperature

$t$ : Top of the test section

$w$ : Cooling water film

1: Inlet

2: Outlet
6.

7. performance of slit-fin-and-tube heat exchangers operating under wet-surface conditions. Journal of Heat Transfer, 2009. 131(5): p. 051802 .

8. Alhusseini, A.A., K. Tuzla, and J.C. Chen, Falling film evaporation of single component liquids. International journal of heat and mass transfer, 1998. 41(12): p. 1623-1632.

9. Jiao, B., et al., Liquid film dryout model for predicting critical heat flux in annular two-phase flow. Journal of Zhejiang University Science A, 2009. 10(3): p. 398-417.

10. Mikielewicz, J. and D. Mikielewicz, A simple dissipation model of circular hydraulic jump. International Journal of Heat and Mass Transfer, 2009. 52(1): p. 17-21.

11. Volle, F., et al., Practical application of inverse heat conduction for wall condition estimation on a rotating cylinder. International Journal of Heat and Mass Transfer, 2009. 52(1): p. 210-221.

12. Grigore, R., et al., Study Regarding the Influence of the Plate Heat Exchanger Configuration on Its Performance. WSEAS Transactions on heat and Mass Transfer, 2010. 5: p. 133-142.

13. Rahman, M. and P. Injeti, HEAT TRANSFER IN MICROTUBE OR MICROCHANNEL WITH PROTRUSIONS. Frontiers in Heat and Mass Transfer (FHMT), 2011. 2(1).

14. Fan, Y. and I. Hassan, Experimental Investigation of Flow Boiling Instability in a Single Horizontal Microtube With and Without Inlet Restriction. Journal of Heat Transfer, 2012. 134(8): p. 081501.

15. Bai, L., G. Lin, and G. Peterson, Evaporative Heat Transfer Analysis of a Heat Pipe With Hybrid Axial Groove. Journal of Heat Transfer, 2013. 135(3): p. 031503.

16. Kumar, R., Enhancement in Evaporative Effectiveness of an Evaporative Tubular Heat Dissipator Using Experimental Design Approach. Heat Transfer-Asian Research, 2014.

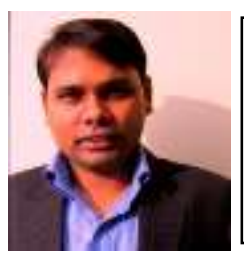

Dr. Rajneesh, Assistant Professor at NITKuruksketra, India, in the Department of Mechanical Engineering.

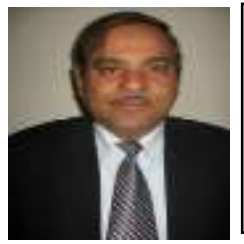

Dr Raj Kumar, Professor at DCR University of Science and Technology, Murthal, Sonepat, India, in the Department of Mechanical Engineering.

\section{References}

1. Lyle, O., G. Britain, and F.E. Committee, The efficient use of steam 1947: HM Stationery Office.

2. Hartely, D. and W. Murgatroyd, Criteria for the break-up of thin liquid layers flowing isothermally over solid surface. Int. J. Heat Mass Transfer, 1964. 7(9): p. 1003-1015.

3. Bonacina, C., S. Del Giudice, and G. Comini, Dropwise evaporation. Journal of Heat Transfer, 1979. 101(3): p. 441-446.

4. Ganic, E. and M. Roppo, An experimental study of falling liquid film breakdown on a horizontal cylinder during heat transfer. Journal of Heat Transfer, 1980. 102(2): p. 342-346.

5. Lin, Y., et al., Measured film cooling effectiveness of three multihole patterns. Journal of heat transfer, 2006. 128(2): p. 192197. 